\title{
Experimental Investigation of the Rigid Polyurethane Foam Granulates Thermal Properties
}

\author{
Artur Miros \\ Institute of Mechanised Construction \& Rock Mining, Branch in Katowice \\ al. Korfantego 193 A, 40-157 Katowice, Poland \\ a.miros@imbigs.pl
}

\section{Extended Abstract}

Due to various interesting properties the polyurethane is very common and often used material. The range of polyurethane use expands from automotive applications, through medical and household appliances, footwear to sealants, elastomers on floors and different applications as thermal insulation products. Such vary applications come from excellent properties such as e.g. very low thermal conductivity and long lifetime [1]. On the other hand such wide and common use implies a lot of PUR waste and problems connected with it. Among options for polyurethane recycling: chemical and thermo chemical processing, energy recovery and mechanical recycling [2], the last option allows, after regrinding, to obtain PUR granulate.

This experimental investigation of rigid polyurethane foam granulates shows changes of thermal properties in case of size of granules [3], and their mixes.

Samples of PUR granulates were obtained after mechanical regrinding treatment of the PUR sandwich thermal insulation panels. Gained granulates were separated on six granulometric fractions: 0-6, 6-12.5, 12.5-20, 20-25, 25-31.5, 31.5-50 mm by sieving. Mixes of differ granulometric fractions were prepared by taking $30 \%$ of mass of one PUR granulometric fraction and $70 \%$ of mass of second fraction. Density and thermal conductivity of six granulometric fractions and samples of their mixes $\left(30 \%\right.$ one fraction and $70 \%$ second fraction) were measured. The thermal conductivity $\lambda_{10}[\mathrm{~W} / \mathrm{m} \cdot \mathrm{K}]$ at mean temperature $10{ }^{\circ} \mathrm{C}$ and temperature difference of hot and cold plates $\Delta \mathrm{T}=20 \mathrm{~K}$ were measured according EN 12667. The thermal properties measurement was performed on the heat flow meter apparatus (HFM 600, LaserComp) with dimension of the plates: $600 \times 600 \mathrm{~mm}$. Particular samples were loosely strewn in EPS frame with inner diameter $550 \times 550 \mathrm{~mm}$ and $100 \mathrm{~mm}$ height. Each sample (PUR granulometric fraction or mix of fractions) was measured at least three times, every time the EPS frame was filled in by new portion of prepared sample.

The results of thermal conductivity for six granulometric fractions: 0-6, 6-12.5, 12.5-20, 20-25, 25-31.5, 31.5-50 mm showed non-linear (second order polynomial) change of $\lambda_{10}$ values with minimum of the value in $\lambda_{10}=0.0444[\mathrm{~W} / \mathrm{m} \cdot \mathrm{K}]$ for 6-12.5 mm granulates. The range of thermal conductivity changes were from $\lambda_{10}=0.0536[\mathrm{~W} / \mathrm{m} \cdot \mathrm{K}]$ for $0-6 \mathrm{~mm}$ granulates to $\lambda_{10}=0.1332[\mathrm{~W} / \mathrm{m} \cdot \mathrm{K}]$ for $31.5-50 \mathrm{~mm}$ granulates.

The thermal conductivity results of mixed granulometric fractions showed significant widening of the range of $\lambda_{10}$ values towards lower values comparing to non-mixed six granulometric fractions. Also, results showed influence of the smallest $(0-$ $6 \mathrm{~mm}$ ) fraction of PUR granulates on decreasing $\lambda_{10}$ value of the mixed granulometric fractions.

Finding the mixed granulometric fractions with the lowest thermal conductivity value allows to reuse PUR granulate waste as a loose in-situ thermal insulation material.

\section{References}

[1] K. M. Zia, H. N. Bhatti, I. A. Bhatti, "Methods for polyurethane and polyurethane composites, recycling and recovery: A review," Reactive \& Functional Polymers, vol. 67, pp. 675-692, 2007.

[2] E. Weigand, "Properties and application of recycled polyurethanes," J. Branderup, M. Bittner, G. Menges, W. Micheali (Eds.), Recycling and Recovery of Plastics, Hanser Publishers, Münich, Germany, 1996.

[3] J. Zach, V. Novak, J. Hroudova., "Utilisation of Polyurethane (PUR) Granulate in Development of New Insulating Materials," Advanced Materials Research, vol. 1000, pp. 133-136, 2014. 